\title{
On mathematical illusions
}

\author{
DONALD I. A. MacLEOD* \\ Institute of Molecular Biophysics, Florida State University, Tallahassee Florida 32306 \\ VEIJO VIRSU \\ University of Helsinki, Helsinki, Finland \\ and \\ R. H. S. CARPENTER \\ Physiological Laboratory, University of Cambridge, Cambridge, England
}

\begin{abstract}
A criticism of Walker's (1973) paper on the grounds that its physiological premises lack support, that it misrepresents the theoretical position of Blakemore, Carpenter, and Georgeson (1970), and that its theory is contradicted by existing evidence.
\end{abstract}

Walker (1973) recently presented an extensive mathematical treatment of the perceptual errors occurring in some geometrical illusions and aftereffects. His theory is based on the idea that "spurious excitations" can arise from the error-inducing lines of illusion figures. These excitations are supposed to bias the representations of contour orientations and locations in the brain. The idea is an interesting one, and Walker's claim to have derived a range of illusions from it deserves attention. But Walker's physiological premises lack support, his paper seems to contain a number of misrepresentations, and-most important-his theory is contradicted by existing evidence.

\section{THE PHYSIOLOGICAL PREMISES}

To account for the large errors made when judging illusory displays, Walker has to suppose that these displays excite not only those cells whose receptive field centers are crossed by some contour, but also cells whose receptive field centers are separated from any contour by considerable distances-distances of up to five times the radius of the receptive field center of retinal ganglion cells (Walker, 1973, p. 469 and Fig. 2), or approximately the radius of the receptive field surround (p. 473). The model requires that it should make no difference whether the stimulating contour crosses the center, or only the surround, of a cell's receptive field; and Walker's equations show that the model predicts almost no illusion if only center stimulation leads to excitation $(\mathrm{q}=1$ in Walker's Eq. 2). The implied equivalence of center and surround is an unorthodox assumption and is

*Supported by NSF Grant GU-2612 and NIH Grant EYO0-68401-VIS to W. A. H. Rushton. difficult to justify, since center and surround responses are of opposite polarity (Enroth-Cugell \& Pinto, 1972). A second vital assumption in Walker's theory is that excitation can and does occur between two lines separated by less than five receptive field-center diameters, but does not invade the region outside the pair of lines (Walker, 1973, Fig. 2 and p. 470). Since there appears to be no basis whatever for this arbitrary assumption, it is important to realize that Walker gives no arguments to justify it, even though it is fundamental to his theory.

\section{MISREPRESENTATIONS}

Walker misrepresents the theoretical position of Blakemore, Carpenter, and Georgeson (1970), who explicitly assume that the inhibition which gives rise to their illusion is an orientation-dependent inhibition of cortical orientation-detecting cells [a phenomenon subsequently reported by Blakemore and Tobin (1972)], not a distance-dependent inhibition of retinal cells that code only local illumination. Their explanation is therefore quite consistent with their experimental observations, in spite of contrary claims by Walker in two sections of his paper.

Furthermore, the apparent agreement of Walker's own treatment with the Blakemore et al. results is actually the happy outcome of an unfortunate error. Walker has based his theory entirely on a figure in which both an acute angle and the complementary obtuse angle are present; but Blakemore et al in their experiment used configurations of a different type, in which only one angle-acute or obtuse-was present. Using this display, acute angles were found to expand, as Walker predicts. But obtuse angles were found to contract; yet the proper prediction from Walker's theory in this case is that "spurious 
excitation" would occur inside the obtuse angle and cause expansion, not contraction. Thus the data of Blakemore et al. for obtuse angles categorically contradict Walker's theory.

On p. 480 of Walker's paper, it is claimed that "the effect of the surround will therefore be basically multiplicative ... That this is the case has been established by Enroth-Cugell and Pinto." This is a complete misunderstanding of Enroth-Cugell and Pinto's conclusions. What they observed was that center and surround responses simply add together (Enroth-Cugell \& Pinto, 1972, p. 404); and they suggest that their results specifically exclude a multiplicative interaction.

It seems to us, also, that Walker misinterprets his own theory when he discusses the results of Weintraub and Krantz. (1971), which contradict the theory; for we cannot understand how spurious excitations generated by the sides of an acute angle could displace the apparent apex away from the bisector of the angle as indicated in Walker's Fig. 8. If spurious excitations arise in cells with receptive field centers between the lines, the apparent apex will presumably lic between the lines and not outside them.

\section{CONTRARY EVIDENCE}

In addition to the contraction of obtuse angles observed by Blakemore et al, there are several other results which contradict Walker's theory but which he omits to mention. In cyclopean view (Julesz, 1971), processes in the monocular pathways are unable to contribute to the illusion; yet the Poggendorff and Mueller-Lyer illusions appear to their full extent when observed in this way (Julesz, 1971, pp. 31, 226). This is also true of figural aftereffects (Walker \& Kruger, 1972). Walker's theory attaches overwhelming importance to the vertices of illusion figures: in particular, a figure in which the vertices are removed to the extent that the converging lines never come as close to each other as $\lambda$ (Fig. 2, p. 469) should show no effect whatever. This is clearly contradicted by the results of Cumming (1968): figures in which the vertices have been removed can still give visual illusions.
Finally, it is known that the Poggendorff illusion (Weintraub \& Krantz, 1971) and the angle-expansion phenomenon (Carpenter \& Blakemore, 1974) depend strongly on the orientation of the test figure on the retina. This is easily explained-indeed expected-on the basis of cortical interactions between orientation detectors, but is incompatible with Walker's model, the predictions of which are independent of the orientation of the display. These strong objections apply not only to Walker's theory but also to all retinal theories of the illusions.

It therefore seems clear to us that the extensive set of equations introduced by Walker would have been much more meaningful if he had been more careful in selecting his qualitative premises and had made these premises more explicit.

\section{REFERENCES}

Bi.akemore, C., Carpenter, R. H. S., \& Georgeson, M. A. Lateral inhibition between orientation detectors in the human visual system. Nature, 1970, 228, 37-39.

Blakemore, C., \& ToBin, E. A. Lateral inhibition between orientation detectors in the cat's visual cortex. Experimental Brain Research, 1972, 15, 439-440.

Carpenter, R. H. S.. \& Blakemore, C. Interactions between orientations in human vision. Experimental Brain Research, 1974, in press.

Cumming, G. D. A criticism of the diffraction theory of some geometrical illusions. Perception \& Psychophysics, 1968, 4, 375-376.

Enroth-Cugell. C., \& Pinto, L. H. Properties of the surround response mechanism of cat retinal ganglion cells and centresurround interaction. Journal of Physiology [London], 1972, 220, 403-439.

Julesz, B. Foundations of cyclopean perception. Chicago: Chicago University Press, 1971 .

WALKER, E. H. A mathematical theory of optical illusions and figural aftereffects. Perception \& Psychophysics, 1973, 13, $467-486$.

WALKER, J. T., \& KRUGER, M. W. Figural aftereffects in randomdot stereograms without monocular contours. Perception, 1972. 1. $187-192$.

Weintraub, D. J., \& Krantz, D. H. The Poggendorff illusion: Amputations, rotations, and other perturbations. Perception \& Psychophysics, 1971, 10, 257-274.

(Received for publication September 24, 1973; revision received March $6,1974$. 